\title{
Thermal-hydraulic analysis of LTS cables for the DEMO TF coil using simplified models*
}

\author{
Monika Lewandowska, \\ Aleksandra Dembkowska
}

\begin{abstract}
The conceptual design activities for the DEMOnstration reactor (DEMO) - the prototype fusion power plant - are conducted in Europe by the EUROfusion Consortium. In 2015, three design concepts of the DEMO toroidal field (TF) coil were proposed by Swiss Plasma Center (EPFL-SPC, PSI Villigen), Italian National Agency for New Technologies (ENEA Frascati), and Atomic Energy and Alternative Energies Commission (CEA Cadarache). The proposed conductor designs were subjected to complete mechanical, electromagnetic, and thermal-hydraulic analyses. The present study is focused on the thermal-hydraulic analysis of the candidate conductor designs using simplified models. It includes (a) hydraulic analysis, (b) heat removal analysis, and (c) assessment of the maximum temperature and the maximum pressure in each conductor during quench. The performed analysis, aimed at verification whether the proposed design concepts fulfil the established acceptance criteria, provides the information for further improvements of the coil and conductors design.
\end{abstract}

Keywords: DEMO $\bullet$ tokamak $\bullet$ low $T_{c}$ superconductors $\bullet$ toroidal field coil $\bullet$ thermal-hydraulic analysis

\author{
M. Lewandowska ${ }^{凶}$ \\ Institute of Physics, \\ Faculty of Mechanical Engineering and Mechatronics, \\ West Pomeranian University of Technology, Szczecin, \\ 48 Piastów Ave., 70-311 Szczecin, Poland, \\ Tel.: +48 91449 4405, Fax: +48 91449 4181, \\ E-mail: monika.lewandowska@zut.edu.pl
}

\section{A. Dembkowska \\ Faculty of Mechanical Engineering and Mechatronics, West Pomeranian University of Technology, Szczecin, 19 Piastów Ave., 70-310 Szczecin, Poland}

Received: 10 June 2016

Accepted: 8 November 2016

\section{Introduction}

The International Thermonuclear Experimental Reactor (ITER) is designed to be the first fusion reactor, which will reach the energy breakeven point, that is, generate more power than it uses to heat and confine plasma. The next step machine is the DEMOnstration reactor (DEMO). In contrast to ITER, which is a research-type tokamak, DEMO is planned to be the prototype fusion power plant, which will generate grid electricity at the level of a few hundred megawatts.

The basic elements of the magnet system of a tokamak are toroidal field (TF) and poloidal field (PF) coils, used to confine plasma, as well as the central solenoid (CS), inducing the heating current flow in a plasma ring. Owing to the very high requirements for operation (e.g. operating currents of several tens of kiloampere), all magnets in ITER, as well as those designed for DEMO, will be wound with superconducting cables. Superconducting magnet system is the most expensive part of a tokamak. DEMO should demonstrate the economic attractiveness of fusion power plants, so designers of the DEMO magnets have

\footnotetext{
*This paper is based on a presentation given at 13th Kudowa Summer School "Towards Fusion Energy", Kudowa Zdrój, Poland, 13-17 June 2016.
} 
to reconcile the fulfilment of very high requirements for operation and reliability with the cost reduction.

Since 2014, the magnet system project team under the lead of EUROfusion Consortium has carried out a broad range of design and assessment studies for DEMO [1], including activities both on low $T_{c}$ superconductor (LTS) and high $T_{c}$ superconductor (HTS). The activities based on the fully established LTS technology were focused mainly on the dimensioning and designing of the TF coils, which could fulfil the specific DEMO requirements, but initial studies of the CS system were also commenced. The parallel HTS research and development (R\&D) activities included studies, testing, and development of various HTS cable concepts, such as Roebel assembled coated conductor (RACC), Rutherford cable with RACC strands, conductor on round core (CORC), and twisted stack cable [2, 3], with the overall goal of selecting the most promising concepts for future fusion applications. Our present study that is focused on the thermal-hydraulic analysis of the most recent designs of the DEMO TF winding pack is within the range of LTS activities.

\section{Conductors' characteristics}

According to the present design, DEMO reactor will consist of sixteen TF coils with the major radius of torus of about $9 \mathrm{~m}$. Three concepts of the DEMO TF winding pack, called WP\#1, WP\#2, and WP\#3, were proposed in 2015 by Swiss Plasma Center (EPFL-SPC), Italian National Agency for New Technologies (ENEA), and Atomic Energy and Alternative Energies

Table 1. Conductor parameters used in the analysis

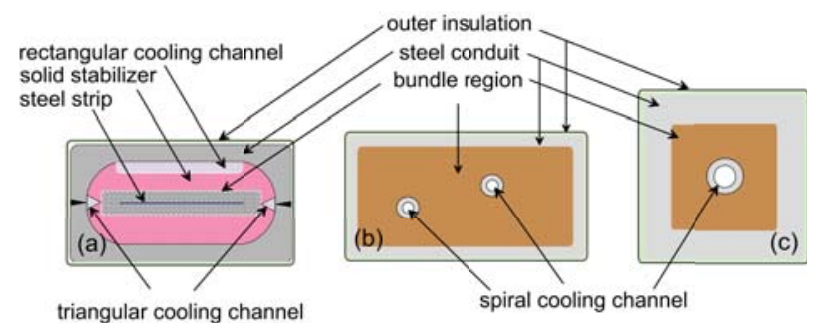

Fig. 1. Schematic layout of the (a) WP\#1, (b) WP\#2, and (c) WP\#3 conductors.

Commission (CEA), respectively, as the improved versions of the 2014 designs [1]. The 2015 design of the DEMO TF winding pack consists of

(a) WP\#1 (SPC design): six double layers (DLs) wound using flat multistage cables with two-side equilateral triangle cooling channels and one rectangular cooling channel (Fig. 1a) [4],

(b) WP\#2 (ENEA design): six DLs wound using rectangular cable-in-conduit conductors (CICCs) with two spiral cooling channels (Fig. 1b) [5],

(c) WP\#3 (CEA design): eight double pancakes (DPs) wound using a square CICC with a central spiral cooling channel (Fig. 1c) [6].

In the WP\#3 design, only one type of the $\mathrm{Nb}_{3} \mathrm{Sn}$ conductor is used, whereas in WP\#1 and WP\#2, each DL has a different conductor grade. The inner DLs (four in WP\#1 and five in WP\#2) located in the high magnetic field are made of $\mathrm{Nb}_{3} \mathrm{Sn}$, whereas the remaining outer DLs in the low field region use NbTi. The WP\# 1 conductors, with several cooling channels of different shapes and the solid stabilizer,

WP\#1 (SPC design)

\begin{tabular}{lccccccccccccc}
\hline $\mathrm{DL}$ & $\begin{array}{c}L \\
{[\mathrm{~m}]}\end{array}$ & $\begin{array}{c}\phi \\
{[-]}\end{array}$ & $\begin{array}{c}A_{\mathrm{He}, B} \\
{\left[\mathrm{~mm}^{2}\right]}\end{array}$ & $\begin{array}{c}D_{h, B} \\
{[\mathrm{~mm}]}\end{array}$ & $\begin{array}{c}A_{s c} \\
{\left[\mathrm{~mm}^{2}\right]}\end{array}$ & $\begin{array}{c}A_{\mathrm{Cu} 1} \\
{\left[\mathrm{~mm}^{2}\right]}\end{array}$ & $\begin{array}{c}A_{\mathrm{Cu} 2} \\
{\left[\mathrm{~mm}^{2}\right]}\end{array}$ & $\begin{array}{c}A_{\mathrm{Steel}} \\
{\left[\mathrm{mm}^{2}\right]}\end{array}$ & $\begin{array}{c}B_{0} \\
{[\mathrm{~T}]}\end{array}$ & $\begin{array}{c}A_{\mathrm{He}, T r} \\
{\left[\mathrm{~mm}^{2}\right]}\end{array}$ & $\begin{array}{c}D_{h, T r} \\
{[\mathrm{~mm}]}\end{array}$ & $\begin{array}{c}A_{\mathrm{He}, R e c} \\
{\left[\mathrm{~mm}^{2}\right]}\end{array}$ & $\begin{array}{c}D_{h, R e c} \\
{\left[\mathrm{~mm}^{2}\right.}\end{array}$ \\
\hline 1 & 848 & 0.20 & 85 & 0.53 & 153 & 153 & 538 & 843 & 12.33 & & & 140 & 7.18 \\
2 & 857 & 0.20 & 72 & 0.49 & 88 & 168 & 523 & 1029 & 10.45 & & 88 & 6.77 \\
3 & 866 & 0.20 & 63 & 0.59 & 68 & 135 & 555 & 1259 & 9.04 & 8 & 2.48 & 44 & 5.87 \\
4 & 875 & 0.20 & 46 & 0.51 & 50 & 100 & 590 & 1521 & 7.51 & & & 40 & 5.71 \\
5 & 886 & 0.28 & 166 & 0.62 & 163 & 244 & 448 & 1829 & 5.78 & & 40 & 5.71 \\
6 & 808 & 0.28 & 128 & 0.71 & 125 & 188 & 503 & 1478 & 5.38 & & 40 & 5.71 \\
\hline
\end{tabular}

WP\#2 (ENEA design)

\begin{tabular}{|c|c|c|c|c|c|c|c|c|c|c|c|}
\hline DL & $\begin{array}{c}L \\
{[\mathrm{~m}]}\end{array}$ & $\begin{array}{c}\phi \\
{[-]}\end{array}$ & $\begin{array}{c}A_{\mathrm{He}, B} \\
{\left[\mathrm{~mm}^{2}\right]}\end{array}$ & $\begin{array}{c}D_{h, B} \\
{[\mathrm{~mm}]}\end{array}$ & $\begin{array}{c}A_{s c} \\
{\left[\mathrm{~mm}^{2}\right]}\end{array}$ & $\begin{array}{c}A_{\mathrm{Cu} 1} \\
{\left[\mathrm{~mm}^{2}\right]}\end{array}$ & $\begin{array}{c}A_{\mathrm{Cu} 2} \\
{\left[\mathrm{~mm}^{2}\right]}\end{array}$ & $\begin{array}{c}A_{\text {Steel }} \\
{\left[\mathrm{mm}^{2}\right]}\end{array}$ & $\begin{array}{l}B_{0} \\
{[\mathrm{~T}]}\end{array}$ & $\begin{array}{c}D_{\text {in }} \\
{[\mathrm{mm}]}\end{array}$ & $\begin{array}{c}D_{\text {out }} \\
{[\mathrm{mm}]}\end{array}$ \\
\hline 1 & 747 & 0.27 & 399 & 0.57 & 283 & 283 & 474 & 725 & 12.1 & \multirow{6}{*}{5} & \multirow{6}{*}{7} \\
\hline 2 & 755 & 0.25 & 334 & 0.54 & 141 & 141 & 687 & 955 & 10.0 & & \\
\hline 3 & 763 & 0.25 & 321 & 0.54 & 106 & 106 & 721 & 1212 & 8.8 & & \\
\hline 4 & 773 & 0.25 & 298 & 0.57 & 63 & 63 & 742 & 1475 & 7.1 & & \\
\hline 5 & 783 & 0.25 & 291 & 0.57 & 47 & 47 & 759 & 1760 & 5.5 & & \\
\hline 6 & 706 & 0.28 & 353 & 0.59 & 65 & 104 & 673 & 2171 & 3.9 & & \\
\hline
\end{tabular}

WP\#3 (CEA design)

\begin{tabular}{cccccccccccc}
\hline $\mathrm{DP}$ & $\begin{array}{c}L \\
{[\mathrm{~m}]}\end{array}$ & $\begin{array}{c}\phi \\
{[-]}\end{array}$ & $\begin{array}{c}A_{\mathrm{He}, B} \\
{\left[\mathrm{~mm}^{2}\right]}\end{array}$ & $\begin{array}{c}D_{h, B} \\
{[\mathrm{~mm}]}\end{array}$ & $\begin{array}{c}A_{\text {sc }} \\
{\left[\mathrm{mm}^{2}\right]}\end{array}$ & $\begin{array}{c}A_{\mathrm{Cu} 1} \\
{\left[\mathrm{~mm}^{2}\right]}\end{array}$ & $\begin{array}{c}A_{\mathrm{Cu} 2} \\
{\left[\mathrm{~mm}^{2}\right]}\end{array}$ & $\begin{array}{c}A_{\text {Steel }} \\
{\left[\mathrm{mm}^{2}\right]}\end{array}$ & $\begin{array}{c}B_{0} \\
{[\mathrm{~T}]}\end{array}$ & $\begin{array}{c}D_{\text {in }} \\
{[\mathrm{mm}]}\end{array}$ & $\begin{array}{c}D_{\text {out }} \\
{[\mathrm{mm}]}\end{array}$ \\
\hline $1-8$ & 364 & 0.29 & 651 & 0.57 & 383 & 387 & 752 & 2559 & 12.27 & 8 & 10 \\
\hline
\end{tabular}


underwent a major change with respect to the previous designs, whereas the other concepts were subjected to some smaller modifications.

The conductors' parameters essential for our analysis are compiled in Table 1 , where $L$ is the length of the shorter cable in each DL (WP\#1 and WP\#2) or the cable length in each single pancake (WP\#3), $\phi$ is the bundle void fraction, $A$ is the component cross section, $D_{h}$ is the hydraulic diameter, $D_{\text {in }} / D_{\text {out }}$ is the inner/outer diameter of a spiral cooling channel, and $B_{0}$ is the maximum expected magnetic flux density at the nominal operating current $I_{0}$ equal to $63.3 \mathrm{kA}$ (WP\#1), $70.8 \mathrm{kA}$ (WP\#2), or $111.6 \mathrm{kA}$ (WP\#3). Indices $B, T r$, and Rec refer to the bundle region, triangle channel, and rectangular channel, respectively; sc denotes superconductor; $\mathrm{Cu} 1$ is the copper in superconducting strands, with $R R R=100$; and $\mathrm{Cu} 2$ is the copper in pure copper strands and in the solid stabilizer (WP\#1), with RRR $=400,450$, and 300 in the WP\#1, WP\#2, and WP\#3 design, respectively. The spiral used in the cooling channels of WP\#2 has a strip width of $3.6 \mathrm{~mm}$ and open area of $40 \%$, whereas the detailed geometry of the spiral in WP\#3 has not been specified yet.

\section{Model assumptions}

The thermal-hydraulic analysis of all the considered conductors was carried out according to the methodology developed in our earlier studies [7-9] of the 2012-2014 DEMO TF coil designs. It consisted of the following three stages:

a) hydraulic analysis - calculation of the mass flow rates in each conductor at operating conditions during the dwell time, that is, assuming no heat deposition in conductors, based on the 1-D steady-state momentum balance equation for uncompressible flow, and using various friction factor correlations available in literature,

b) heat removal analysis - calculation of the mass flow rates as well as the temperature and pressure profiles along each conductor as functions of the heat deposition rate, based on the 1-D steady-state energy and momentum conservation equations for compressible flow, aimed at the assessment of the temperature margin at the expected nuclear heat (NH) load,

c) assessment of the maximum temperature and the maximum pressure in each conductor dur- ing quench, based on the transient 0-D energy conservation equation.

The detail presentation of the simplified models used in our analysis, including the governing equations, is included in [7]. The heat removal model was modified to account for the increased number of cooling channels in the WP\#1 and WP\#2. The assumed cooling conditions for the DEMO TF coil are similar to those of ITER, that is, the coil is forced-flow cooled by supercritical helium at $T_{i n}=4.5 \mathrm{~K}$ and $p_{\text {in }}=0.6 \mathrm{MPa}$, whereas the expected value of pressure drop at operating conditions is $\Delta p=0.1 \mathrm{MPa}$.

For predicting the friction factor, $f$, in the bundle regions, two porous medium analogy correlations were used: the one based on the Darcy-Forchheimer momentum balance equation $\left(f_{\mathrm{DF}}\right)$ taken from [10], and the modified one $\left(f_{M}\right)$ [11]. For the turbulent flow in the cooling channels of WP\#1, we used the Bhatti-Shah correlation for turbulent flow in circular or non-circular ducts $\left(f_{\mathrm{BS}}\right)$ [12]. For flows in the spiral cooling channels of WP\#2, we used two friction factor correlations, $f_{Z a n 1}$ and $f_{Z a n 2}$, taken from [13] and [14], respectively. Owing to the lack of detailed specification of the spiral geometry in WP\#3, the friction factor in this channel $\left(f_{\text {spiral }}\right)$ was calculated with the experimental correlation used in $[9,15]$.

The expected NH load in each conductor was obtained by integrating, per given layer in layer-wound coil or per given turn in pancake-wound coil, the formula $[9,15]$ :

$$
P_{\mathrm{NH}}=50 \mathrm{~W} / \mathrm{m}^{3} \cdot \exp (-r / \lambda)
$$

where $\lambda=0.140 \mathrm{~m}$ is the decay length of the $\mathrm{NH}$ deposition and $r$ is the radial distance from the inner side edge of the TF case. The resulting NH load in WP\# 1 and WP\#2 is shown in Table 2. In the layer-wound WP\#1 and WP\#2, NH is deposited evenly throughout each conductor; therefore, the heat deposition per unit length of conductor is constant, equal to $P_{\mathrm{NH}} / L$. In the pancake-wound WP\#3, the $\mathrm{NH}$ load is different in different turns (see Fig. 2).

The simplified quench model assumes the extreme scenario for the maximum pressure, that is, whole conductor in normal state and all channels of flow blocked. Actually, during a quench, most of the helium is expelled from a conductor, which results in pressure reduction, especially close to the conductor inlet and outlet. The assumed instanta-

Table 2. The expected NH load, total mass flow rate, and temperature margin in the WP\#1 and WP\#2 designs calculated with the heat removal model, $T_{c s}$ values were taken from $[4,16]$

\begin{tabular}{|c|c|c|c|c|c|c|c|c|c|c|}
\hline \multirow{2}{*}{ Layer } & \multicolumn{5}{|c|}{ WP\#1 } & \multicolumn{5}{|c|}{ WP\#2 } \\
\hline & $\begin{array}{l}P_{\mathrm{NH}} \\
{[\mathrm{W}]}\end{array}$ & $\begin{array}{c}T_{c s} \\
{[\mathrm{~K}]}\end{array}$ & $\begin{array}{l}\dot{m}_{\text {total }} \\
{[\mathrm{g} / \mathrm{s}]}\end{array}$ & $\begin{array}{l}T_{\text {out }} \\
{[\mathrm{K}]}\end{array}$ & $\begin{array}{c}\Delta T_{\text {marg }} \\
{[\mathrm{K}]}\end{array}$ & $\begin{array}{l}P_{\mathrm{NH}} \\
{[\mathrm{W}]}\end{array}$ & $\begin{array}{c}T_{c s} \\
{[\mathrm{~K}]}\end{array}$ & $\begin{array}{l}\dot{m}_{\text {total }} \\
{[\mathrm{g} / \mathrm{s}]}\end{array}$ & $\begin{array}{l}T_{\text {out }} \\
{[\mathrm{K}]}\end{array}$ & $\begin{array}{c}\Delta T_{\operatorname{marg}} \\
{[\mathrm{K}]}\end{array}$ \\
\hline$\overline{\text { DL1.1 }}$ & 36.7 & 6.55 & 18.46 & 5.04 & 1.51 & 39.6 & 6.90 & 3.86 & 6.16 & 0.74 \\
\hline DL2.1 & 22.7 & 6.09 & 11.53 & 5.04 & 1.05 & 24.3 & 6.84 & 3.34 & 5.86 & 0.98 \\
\hline DL3.1 & 14.4 & 6.16 & 5.78 & 5.14 & 1.02 & 15.1 & 7.18 & 3.31 & 5.50 & 1.68 \\
\hline DL4.1 & 9.0 & 6.05 & 5.22 & 4.99 & 1.06 & 8.8 & 6.61 & 3.22 & 5.19 & 1.42 \\
\hline DL5.1 & 5.8 & 6.11 & 5.97 & 4.83 & 1.28 & 5.0 & 6.74 & 3.18 & 4.96 & 1.78 \\
\hline DL6.1 & 2.5 & 6.19 & 5.74 & 4.70 & 1.49 & 2.8 & 5.64 & 4.00 & 4.77 & 0.88 \\
\hline
\end{tabular}




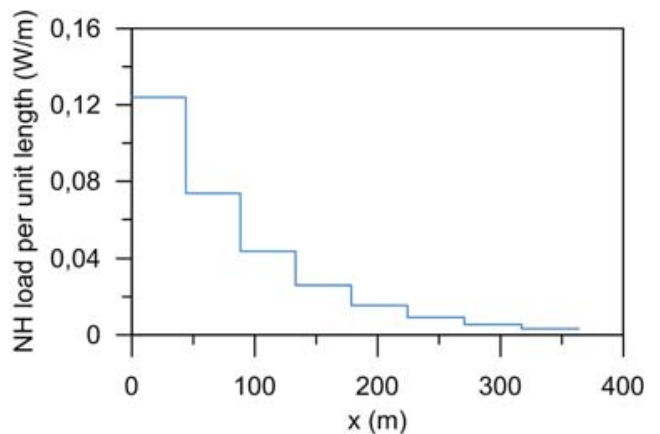

Fig. 2. The expected nuclear heat load map in the WP\#3 conductor.

neous heat transfer between different conductor components results in the most optimistic scenario for the maximum quench temperature. As agreed within the project team [17], we assume that after $3 \mathrm{~s}$ of quench simulation, the fast discharge procedure is triggered, which results in the exponential
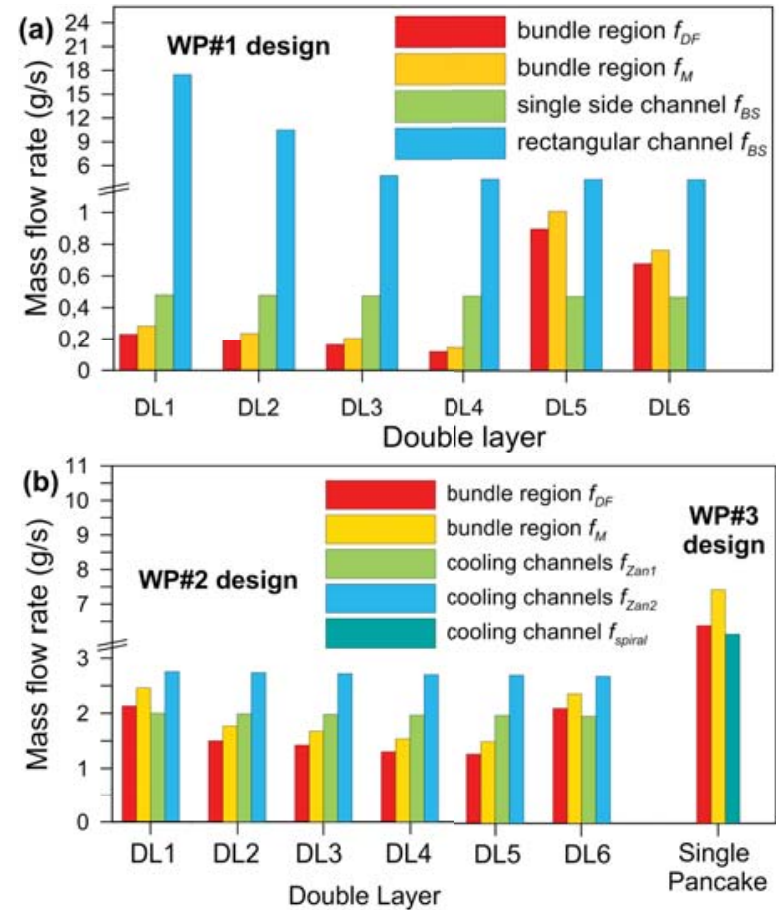

Fig. 3. Mass flow rates in the inner conductor in each DL of WP\# 1 and WP\#2 and in a single pancake of WP\#3, during the dwell time.

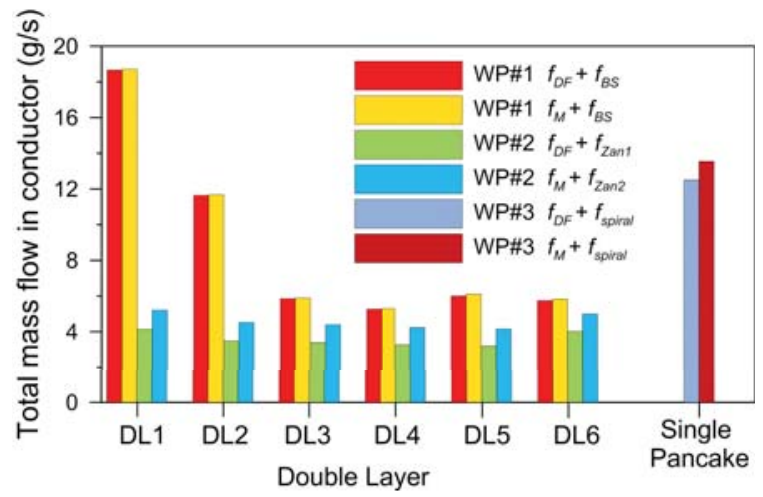

Fig. 4. Total mass flow rate in the inner conductor in each DL of WP\#1 and WP\#2 and in the single pancake of WP\#3. dump of the operating current and magnetic field, with the characteristic time constant equal to $27 \mathrm{~s}$.

\section{Results}

The results of the hydraulic analysis are presented in Figs. 3 and 4. It is seen that the mass flow rates in the bundle regions of WP\#1 $\mathrm{NbTi}$ conductors (DL5-6) are about four times larger than those in the $\mathrm{Nb}_{3} \mathrm{Sn}$ conductors (DL1-4), because of much higher void fraction (see Table 1). Owing to the invariable geometry of side triangle channel in each layer, its mass flow rate is maintained at constant level. From all channels of flow in the WP\# 1 design, the rectangular channels play a significant role in cooling, which provide the largest value of mass flow rates. There is no such strong differentiation of the mass flow in different channels of flow in the WP\#2 and WP\#3 conductors, where the mass flow rates in the bundle regions and the cooling channels are similar (see Fig. 3b).

The porous medium correlation based on the Darcy-Forchheimer momentum balance equation $\left(f_{\mathrm{DF}}\right)$ predicts mass flow rates about $15-23 \%$ smaller than the modified one $\left(f_{M}\right)$. The lower the void fraction, the larger is discrepancy between predictions of $f_{\mathrm{DF}}$ and $f_{M}$ correlations. The predictive capability of different bundle friction factor correlations for conductors with very low void fraction (below 0.25 ) should be verified experimentally. The mass flow rates predicted by $f_{\text {Zan } 1}$ correlation are of about $37 \%$ larger that those resulting from $f_{\text {Zan } 2}$, which indicates a significant uncertainty of mass flow rates in the cooling channels of the WP\#2 design. Even larger uncertainty of the mass flow rate in the central channel of the WP\#3 conductor can also be expected, because the geometry of the spiral in the WP\#3 design has not been specified yet, so the predictive capability of the $f_{\text {spiral }}$ correlation cannot be verified. The most conservative pairs of the friction factor correlations, namely, $f_{\mathrm{BS}}$ and $f_{\mathrm{DF}}$ for the WP\# 1 design, $f_{\mathrm{Zan} 1}$ and $f_{\mathrm{DF}}$ for the $\mathrm{WP} \# 2$, and $f_{\text {spiral }}$ and $f_{\mathrm{DF}}$ for the WP\#3, were chosen to be used in the heat removal analysis.

The total mass flow rate in the first two DLs, subjected to the highest $\mathrm{NH}$ loads during the plasma burn, in the WP\#2 design is much smaller than that in the WP\#1 (see Fig. 4), which may indicate problems with ensuring sufficiently large temperature margin in these DLs of WP\#2. The total mass flow rate in the DEMO TF coil computed for each of the designs using different pairs of the friction factor correlations is presented in Table 3 . The total

Table 3. Total mass flow rates in the DEMO TF coil $(\Delta p=0.1 \mathrm{MPa}$, no heat deposition)

\begin{tabular}{ccc}
\hline Design & $\begin{array}{c}\text { Friction factor } \\
\text { correlations }\end{array}$ & $\begin{array}{c}\text { Total mass flow } \\
\text { in the coil }[\mathrm{g} / \mathrm{s}]\end{array}$ \\
\hline $\mathrm{WP \# 1}$ & $f_{\mathrm{BS}}$ and $f_{\mathrm{DF}}$ & $\min 106.6$ \\
& $f_{\mathrm{BS}}$ and $f_{M}$ & $\max 107.3$ \\
$\mathrm{WP \# 2}$ & $f_{\text {Zan } 1 \text { and } f_{\mathrm{DF}}}$ & $\min 43.3$ \\
& $f_{\text {Zan } 2 \text { and } f_{M}}$ & $\max 55.3$ \\
$\mathrm{WP \# 3}$ & $f_{\text {spiral }}$ and $f_{\mathrm{DF}}$ & $\min 200.3$ \\
& $f_{\text {spiral }}$ and $f_{M}$ & $\max 216.8$ \\
\hline
\end{tabular}


mass flow rate in the WP\#3 coil is about two times larger than that in the WP\#1 coil and about four times larger than that in the WP\#2 coil. Such large differences deserve an attention of the designers. It should also be noted that the total mass flow rate in the WP\# 1 and 2 TF coil is over twice smaller than that in the respective 2014 designs [9].

The main results of heat removal analysis performed for WP\#1 and WP\#2 concepts are presented in Table 2. It is seen that the temperature margin, defined conservatively as $\Delta T_{\operatorname{marg}}=T_{c s}-T_{\text {out }}$ where $T_{c s}$ is the current sharing temperature calculated in $[4$, $16]$ at the maximum expected magnetic field $B_{0}$, is too small, that is, below the $\Delta T_{\operatorname{marg}}>1.5 \mathrm{~K}$ criterion [1], in most of the WP\#1 (DL2-DL5) and WP\#2 (DL1, DL2, DL6) conductors. These potentially problematic conductors require more detailed analysis of the temperature margin using the THEA [18] or 4C [19] code.

The temperature profile along the WP\#3 conductor, calculated at the NH map shown in Fig. 2, is presented in Fig. 5. In the WP\#3 conductor, the most critical point, corresponding to the maximum magnetic field in the first turn, is located at $x_{\text {crit }}=$ $31.88 \mathrm{~m}$. It is seen in Fig. 5 that the temperature margin, defined as $\Delta T_{\text {marg }}=T_{c s}-T\left(x_{\text {crit }}\right)$, is sufficiently large.

The calculated maximum temperature and pressure during quench in the WP\#1-WP\#3 conductors are presented in Fig. 6. It is seen that the maximum quench temperatures resulting from the simplified model are relatively low, that is, below the $150 \mathrm{~K}$ criterion specified in [20]. They may serve as a reference (lower limit) for the maximum

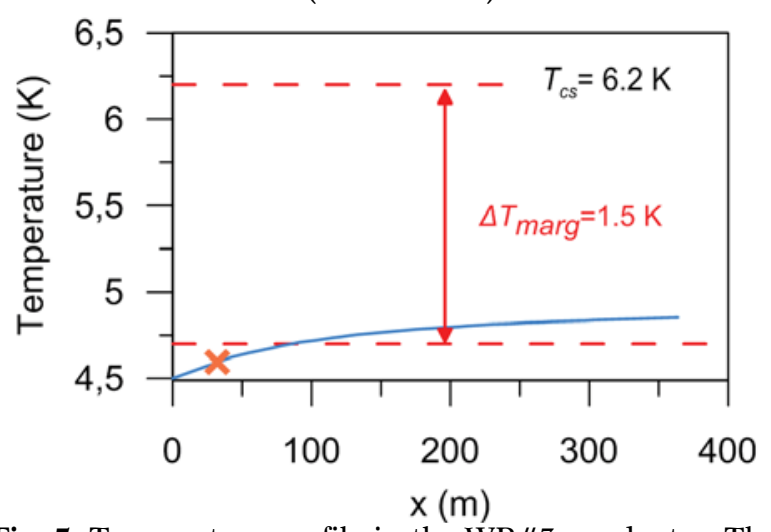

Fig. 5. Temperature profile in the WP\#3 conductor. The critical point is indicated by the symbol ' $\mathrm{x}$ ', $T_{c s}$ values was taken from [6].

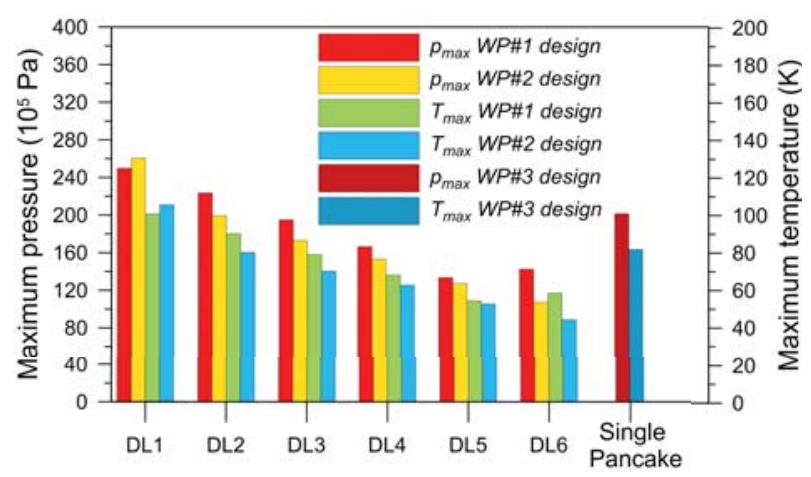

Fig. 6. Maximum quench temperature and pressure in the WP\#1-WP\#3 conductors. quench temperatures in case when quench happens simultaneously along the full conductor length. The maximum pressures calculated using the simplified model may serve as a reference (upper limit) in case when quench happens simultaneously along the full conductor length. It deserves an attention that the maximum quench pressure and temperature in the WP\# 1 and WP\#2 conductors are apparently higher than those in the 2012-2014 designs.

\section{Summary and conclusions}

The performed thermal-hydraulic analysis of the concepts of the LTS DEMO TF coil, proposed in 2015 , shows the need of further improvements of the WP\#1 and WP\#2 designs. The heat removal capability of some WP\#1 and WP\#2 conductors seems insufficient to ensure the specified temperature margin of $1.5 \mathrm{~K}$ in burn conditions. In particular, the design $T_{c s}$ values in the WP\#1 DL2.1 and DL4.1 conductors are too low. They should not be smaller than $6.1 \mathrm{~K}$, because the outlet $\mathrm{He}$ temperature even without heat deposition is $4.60 \mathrm{~K}$ because of the Joule-Thomson effect. Thus, increasing the superconductor cross section in the WP\#1 DL2 and DL4 conductors seems indispensable. More detailed studies of all the potentially problematic cables using the THEA or $4 \mathrm{C}$ code are needed, to decide if increasing helium cross section in cooling channels is necessary to enhance their heat removal capability. The temperature margin in the WP\#3 conductor is sufficiently large.

The minimum total mass flow rate in the coil, in case when there is no heat deposition, was assessed to be 107,43 , and $200 \mathrm{~g} / \mathrm{s}$ for the WP\#1, WP\#2, and WP\#3 design, respectively. These values provide a reference point for designers of the DEMO cryogenic system.

The hot spot temperatures in WP\#1, WP\#2, and WP\#3 conductors resulting from the simplified model adopted in our analysis is lower than $150 \mathrm{~K}$ criterion [20]. However, it should be kept in mind that the simplified model can provide only the estimate of the lower limit of the hot spot temperature and upper limit of pressure in case when quench is initiated simultaneously along the whole conductor length.

Acknowledgments. This work has been carried out within the framework of the EUROfusion Consortium and has received funding from the Euratom Research and Training Programme 2014-2018 under grant agreement No. 633053. The views and opinions expressed herein do not necessarily reflect those of the European Commission. This scientific work was partly supported by the Polish Ministry of Science and Higher Education within the framework of the scientific financial resources in the year 2015 allocated for the realization of the international co-financed project.

The 13th edition of the Kudowa Summer School "Towards Fusion Energy", held in Kudowa Zdrój, Poland on 13-17 June 2016, was supported by the 
Polish Physical Society as well as the Polish Ministry of Science and Higher Education.

\section{References}

1. Zani, L., Bayer, C. M., Biancolini, M. E., Bonifetto, R., Bruzzone, P., Brutti, C., Ciazynski, D., Coleman, M., Duran, I., Eisterer, M., Fietz, W. H., Gade, P. V., Gaio, E., Giorgetti, F., Goldacker, W., Gömöry, F., Granados, X., Heller, R., Hertout, P., Hoa, C., Kario, A., Lacroix, B., Lewandowska, M., Maistrello, A., Muzzi, L., Nijhuis, A., Nunio, F., Panin, A., Petrisor, T., Poncet, J. -M., Prokopec, R., Sanmarti Cardona, M., Savoldi, L., Schlachter, S. I., Sedlak, K., Stepanov, B., Tiseanu, I., Torre, A., Turtù, S., Vallcorba, R., Vojenciak, M., Weiss, K. -P., Wesche, R., Yagotintsev, K., \& Zanino, R. (2016). Overview of progress on the EU DEMO reactor magnet system design. IEEE Trans. Appl. Supercond., 26(4), 4204505. DOI: 10.1109/ TASC.2016.2536755.

2. Fietz, W. H., Barth, Ch., Drotziger, S., Goldacker, W., Heller, R., Schlachter, S. I., \& Weiss, K. -P. (2013). Prospects of high temperature superconductors for fusion magnets and power applications. Fusion Eng. Des., 88, 440-445. DOI: 10.1016/j.fusengdes.2013.03.059.

3. Uglietti, D., Bykovsky, N., Wesche, R., \& Bruzzone, P. (2015). Development of HTS conductors for fusion magnets. IEEE Trans. Appl. Supercond., 25(3), 4202106. DOI: 10.1109/TASC.2014.2364715.

4. Sedlak, K. (2015). TF conductor and WP\#1 design based on 2015 reference. Report WPMAG-MCD-2.1T01 RS02. (IDM reference: EFDA D 2MHQQ5).

5. Muzzi, L., Turtù, S., Fiamozzi Zignāni, C., \& Anemona, A. (2015). Design of 2015 TF Winding Pack Option 2 (WP\#2) and of "ENEA" LTS cable. Report for WPMAG-MCD-2.1-T02 RS02. (IDM reference: EFDA_D_2LF3Z8).

6. Ciazynski, D., \& Torre, A. (2015). TF WP\#3 design based on 2015 EUROfusion configuration. Report WPMAG-MCD 2.1-T003 RS03. (IDM reference: EFDA_D_2MDLUL).

7. Lewandowska, M., \& Sedlak, K. (2014). Thermalhydraulic analysis of LTS cables for the DEMO TF coil. IEEE Trans. Appl. Supercond., 24(3), 4200305. DOI: 10.1109/TASC.2013.2281625.

8. Lewandowska, M., \& Sedlak, K. (2016). Thermalhydraulic analysis of the improved LTS conductor design concepts for the DEMO TF coil. Prz. Elektrotech., 92(4), 179-182. DOI: 10.15199/48.2016.04.39.

9. Lewandowska, M., Sedlak, K., \& Zani, L. (2016). Thermal-hydraulic analysis of the low $T_{c}$ supercon- ductor (LTS) winding pack design concepts for the DEMO toroidal field (TF) coil. IEEE Trans. Appl. Supercond., 26(4), 4205305. DOI: 10.1109/ TASC.2016.2542003.

10. Bagnasco, M., Bottura, L., \& Lewandowska, M. (2010). Friction factor correlation for CICC's based on a porous media analogy. Cryogenics, 50(11/12), 711-719. DOI: 10.1016/j.cryogenics.2010.06.016.

11. Lewandowska, M., \& Bagnasco, M. (2011). Modified friction factor correlation for CICC's based on a porous media analogy. Cryogenics, 51(9), 541-545. DOI: 10.1016/j.cryogenics.2011.07.003.

12. Shah, R. K., \& Sekulić D. P. (2003). Fundamentals of heat exchanger design. New Jersey, USA: Wiley.

13. Zanino, R., Santagati, P., \& Savoldi, L. (2000). Friction factor correlation with application to the central cooling channel of Cable-in-Conduit superconductors for fusion magnets. IEEE Trans. Appl. Supercond., 10(1), 1066-1069.

14. Zanino, R., Giors, S., \& Savoldi-Richard, L. (2007). CFD modelling of ITER cable-in-conduit superconductors. Part III: correlation for the central channel friction factor. In 21st International Cryogenic Engineering Conference (ICEC 21), 17-21 July 2006 (pp. 207-210).

15. Vallcorba, R., Lacroix, B., Ciazynski, D., Torre, A., Nunio, F., Zani, L., Le Coz, Q., Lewandowska, M., \& Coleman, M. (2016). Thermo-hydraulic analyses associated with a CEA design proposal for a DEMO TF conductor. Cryogenics, 80(Pt. 3), 317-324. DOI: 10.1016/j.cryogenics.2016.05.004.

16. Brighenti, A., Bonifetto, R., Savoldi, L., \& Zanino, R. (2016). Preliminary thermal-hydraulic analysis of the performance of the ENEA updated WP during plasma burn. Report for WPMAG-MCD-2.2-T002 D002. (IDM reference: EFDA_D_2N28R4).

17. Lacroix, B., \& Vallcorba, R. (2015). Common approach for quench analyses. Report for WPMAGMCD-2.2. (IDM reference: EFDA_D_2M6DW4).

18. Bottura, L., Rosso, C., \& Breschi, $\bar{M}^{-}{ }^{-}(2000)$. A general model for thermal, hydraulic and electric analysis of superconducting cables. Cryogenics, 40(8/10), 617-626. DOI: 10.1016/S0011-2275(01)00019-4.

19. Savoldi Richard, L., Casella, F., Fiori, B., \& Zanino, R. (2010). The 4C code for the cryogenic circuit conductor and coil modeling in ITER. Cryogenics, 50(3), 167-176. DOI: 10.1016/j.cryogenics.2009.07.008.

20. ITER. (2006). ITER Design Description Document. Magnets. Section 1: Engineering Description. ITER_D_22HV5L v2.2. 